\title{
ESTUDO DA CONCENTRAÇÃO DE ÁCIDO FOSFÓRICO NA HIDRÓLISE DA CASCA DE ARROZ PARA OBTENÇÃO DE AÇÚCARES FERMENTÁVEIS
}

\author{
J. M. MOSCON ${ }^{1}$, J. R. F. SILVA ${ }^{1}$, E. L. FOLETTO ${ }^{1}$, S. L. JAHN ${ }^{1}$, R. C. KUHN ${ }^{1}$, A.CANCELIER ${ }^{1}$, \\ M. A. MAZUTTI ${ }^{1}$ \\ ${ }^{1}$ Universidade Federal de Santa Maria, Departamento de Engenharia Química \\ E-mail para contato: mazutti@ufsm.br
}

\begin{abstract}
RESUMO - O principal objetivo deste estudo foi avaliar a hidrólise da casca de arroz para obtenção de açúcares fermentáveis por rota ácida convencional. Para esta finalidade, a metodologia do planejamento de experimentos foi usada para otimizar a temperatura, teor de umidade e a concentração de ácido fosfórico utilizados, para a obtenção de açúcar fermentável. Os rendimentos obtidos variaram de 6,4 a 143,5 g. $\mathrm{kg}^{-1}$, dependendo das condições estudadas, mostrando que a utilização de um ácido fraco também é interessante, e que a ferramenta de planejamento de experimentos é muito útil para a otimização do processo.
\end{abstract}

\section{INTRODUÇÃO}

O rápido esgotamento dos combustíveis fósseis tem levado o mundo a utilizar fontes renováveis de energia, como os biocombustíveis, a fim de reduzir a total dependência de fontes de energia não renováveis. A crescente industrialização derivou em uma crescente demanda de combustíveis que tentam satisfazer tanto as demandas industriais quanto as domésticas. Os resíduos lignocelulósicos provenientes da agricultura são matérias-primas promissoras para a produção de açúcar em grande escala. Como são resíduos, eles não competem diretamente com a produção de alimentos. Entre as várias biomassas, como uma fonte abundante e renovável, a casca de arroz não é apenas uma fonte potencial de energia, mas também um subproduto com valor agregado (Diaz et al., 2013; Vlaev et al., 2003).

O arroz é uma importante cultura agrícola e é responsável por $20 \%$ da energia nutricional do mundo. A casca de arroz representa cerca de $20 \%$ do peso seco da colheita, sendo um resíduo lignocelulósico abundante, principalmente no estado do Rio Grande do Sul, que é o maior produtor brasileiro de arroz, representando cerca de $50 \%$ de toda a quantidade produzida no país. É um resíduo tão abundante e de baixo valor adicionado pelo seu valor muito baixo como ração animal, porque é um produto de digestibilidade difícil, de baixa densidade e grande quantidade de cinzas/sílica como componentes e características abrasivas (Hickert, 2010). Embora a casca de arroz encontre utilização como combustível em caldeiras industriais, seu alto teor de cinzas e enormes quantidades produzidas 


\section{9 a 22 de outubro de 2014 \\ Florianópolis/SC}

representa graves problemas tecnológicos e ambientais. Por conseguinte, esse resíduo poderia ser utilizado como substrato para fermentação etanólica (Hickert et al., 2013).

Segundo Saha et al. (2005), o alto conteúdo de lignina (16\%) e cinzas (20\%) presentes na casca de arroz dificulta sua conversão a etanol. Uma alternativa para a hidrólise de material lignocelulósico é a utilização de ácido, como ácido sulfúrico ou ácido clorídrico. Porém a utilização de ácido forte é evitada por apresentar desvantagens, como corrosão dos equipamentos, produzir compostos tóxicos como furfural em grande proporção, além de necessitar de sucessivas lavagens do material que foi hidrolisado, causando com isso grande consumo de água, o que acaba encarecendo o processo.

Embora o ácido fosfórico seja cerca de 20 vezes mais caro que o ácido sulfúrico, o interesse no seu uso é que, após a neutralização do hidrolisado, o sal formado é o fosfato de sódio. Este sal pode permanecer nos hidrolisados porque é utilizado como nutriente por microrganismos. Portanto, uma operação de filtração não é necessária com a consequente vantagem: melhorar a economia do processo, evitando a filtração para remover os sais e diminuindo a quantidade de nutrientes necessários para a fermentação. Além disso, o sal não causa problemas ao meio ambiente. Dessa forma, a utilização do ácido fosfórico também pode proporcionar uma oportunidade de co-produto na forma de um componente valioso de fertilizantes para plantas, o que seria uma alternativa para o custo do mesmo. Além disso, com a utilização de um ácido fraco, necessita-se de um menor consumo de água para a neutralização (Gamez et al., 2006; Geddes et al., 2010).

Com base nisso, este artigo tem como objetivo a hidrólise de casca de arroz, utilizando ácido fosfórico como catalisador, visando à obtenção de açúcares com interesses comerciais.

\section{MATERIAL E MÉTODOS}

\subsection{Materiais}

As cascas de arroz utilizadas foram obtidas a partir de uma fábrica de processamento local (Primo Berleze, Santa Maria, RS). As amostras, assim que foram recebidas, foram moídas, peneiradas e mantidas à temperatura de $-18^{\circ} \mathrm{C}$ até a realização dos experimentos. Foi utilizado $10 \mathrm{~g}$ de cascas de arroz em cada ensaio. Foram utilizados como reagentes: ácido fosfórico (85\% p/p, Vetec) e ácido 3,5 dinitrosalicílico (Vetec).

\subsection{Metodologia}

Para os experimentos, foi utilizado um banho termostático (Unique Inc. modelo USC 1800A). As reações foram conduzidas utilizando um béquer com 10 gramas de casca de arroz. O planejamento de experimentos adotado foi do tipo composto central rotacional, para avaliar a influência de três variáveis: temperatura, umidade e concentração de ácido fosfórico, de acordo com a Tabela 1, sendo que as porcentagens de ácido e de água adicionadas à casca de arroz foram realizadas considerando o peso da casca de arroz utilizada na reação. As reações ocorreram por um período de 4 horas. Os dados foram tratados com o software Statistica ${ }^{\circledR} 8.0$ (Statsoft Inc., Tulsa, OK, USA), considerando um nível de $90 \%$ de confiança. 
Tabela 1 - Variáveis e níveis utilizados para o planejamento experimental da hidrólise ácida de casca de arroz

\begin{tabular}{|c|c|c|c|c|c|}
\hline & $-1,68$ & -1 & 0 & +1 & $+1,68$ \\
\hline Umidade (\%) & 40 & 48 & 60 & 72 & 80 \\
\hline Temperatura $\left({ }^{\circ} \mathrm{C}\right)$ & 30 & 37 & 47,5 & 58 & 65 \\
\hline Ácido (\%) & 7,5 & 12,1 & 18,8 & 25,4 & 30 \\
\hline
\end{tabular}

\subsection{Determinação de açúcares redutores}

Após a hidrólise, os açúcares redutores totais da casca de arroz foram extraídos utilizando água destilada, na proporção de $0,1(\mathrm{p} / \mathrm{v})$ adicionados à amostra. Essa mistura foi levada para agitação, por 30 minutos a uma temperatura de $30^{\circ} \mathrm{C}$ e $150 \mathrm{rpm}$. Após esse período, a amostra foi filtrada a vácuo utilizando-se papel filtro qualitativo Whatman $\mathrm{n}^{\circ} 1$, neutralizada com $\mathrm{NaOH}$ até $\mathrm{pH} 5$ e sobrenadante foi utilizado para a determinação dos açúcares redutores totais, de acordo com Miller (1959). Os resultados foram expressos em g ART/kg de casca de arroz.

\section{RESULTADOS E DISCUSSÃO}

A Tabela 2 apresenta os resultados para o delineamento composto central rotacional utilizado neste trabalho, que tem como objetivo a hidrólise ácida de casca de arroz.

Tabela 2 - Planejamento de experimentos realizado (valores codificados e reais), bem como valores de açúcares redutores totais para a hidrólise ácida de casca de arroz

\begin{tabular}{ccccc}
\hline Experimento & $\begin{array}{c}\text { Umidade } \\
(\%)\end{array}$ & $\begin{array}{c}\text { Temperatura } \\
\left({ }^{\circ} \mathrm{C}\right)\end{array}$ & Ácido (\%) & $\begin{array}{c}\text { Açúcares } \\
\text { redutores totais } \\
(\mathrm{g} / \mathrm{kg})\end{array}$ \\
\hline 1 & $48(-1)$ & $37(-1)$ & $12,1(-1)$ & 12,9 \\
2 & $72(1)$ & $37(-1)$ & $12,1(-1)$ & 18,3 \\
3 & $48(-1)$ & $58(1)$ & $12,1(-1)$ & 12,4 \\
4 & $72(1)$ & $58(1)$ & $12,1(-1)$ & 9,1 \\
5 & $48(-1)$ & $37(-1)$ & $25,4(1)$ & 14 \\
6 & $72(1)$ & $37(-1)$ & $25,4(1)$ & 21,6 \\
7 & $48(-1)$ & $58(1)$ & $25,4(1)$ & 143,5 \\
8 & $72(1)$ & $58(1)$ & $25,4(1)$ & 107,4 \\
9 & $40(-1,68)$ & $47,5(0)$ & $18,8(0)$ & 12,3 \\
10 & $80(1,68)$ & $47,5(0)$ & $18,8(0)$ & 6,4
\end{tabular}


Tabela 2 - Continuação.

\begin{tabular}{ccccc}
11 & $60(0)$ & $30(-1,68)$ & $18,8(0)$ & 93,8 \\
12 & $60(0)$ & $65(1,68)$ & $18,8(0)$ & 71,9 \\
13 & $60(0)$ & $47,5(0)$ & $7,5(-1,68)$ & 91,6 \\
14 & $60(0)$ & $47,5(0)$ & $30(1,68)$ & 85,4 \\
15 & $60(0)$ & $47,5(0)$ & $18,8(0)$ & 105,8 \\
16 & $60(0)$ & $47,5(0)$ & $18,8(0)$ & 99,8 \\
17 & $60(0)$ & $47,5(0)$ & $18,8(0)$ & 129,8 \\
\hline
\end{tabular}

De acordo com a Tabela 2, o maior rendimento de açúcares redutores totais foi no ensaio 7, com $143,5 \mathrm{~g}$ ART $/ \mathrm{kg}$ de casca de arroz. Este ensaio consistia de casca de arroz com 48\% de umidade, $25,4 \%$ de ácido fosfórico, conduzido a uma temperatura de $58{ }^{\circ} \mathrm{C}$. Pelo gráfico de Pareto (Figura 1), que mostra aos efeitos das variáveis, observa-se que a umidade quadrática foi significativa negativamente, indicando a presença de um ponto máximo para essa variável. A interação entre as variáveis lineares temperatura e ácido foram positivas significativamente no intervalo avaliado, indicando que um aumento da temperatura e porcentagem de ácido utilizada podem resultar em um aumento do rendimento em açúcares redutores totais da reação de hidrólise.

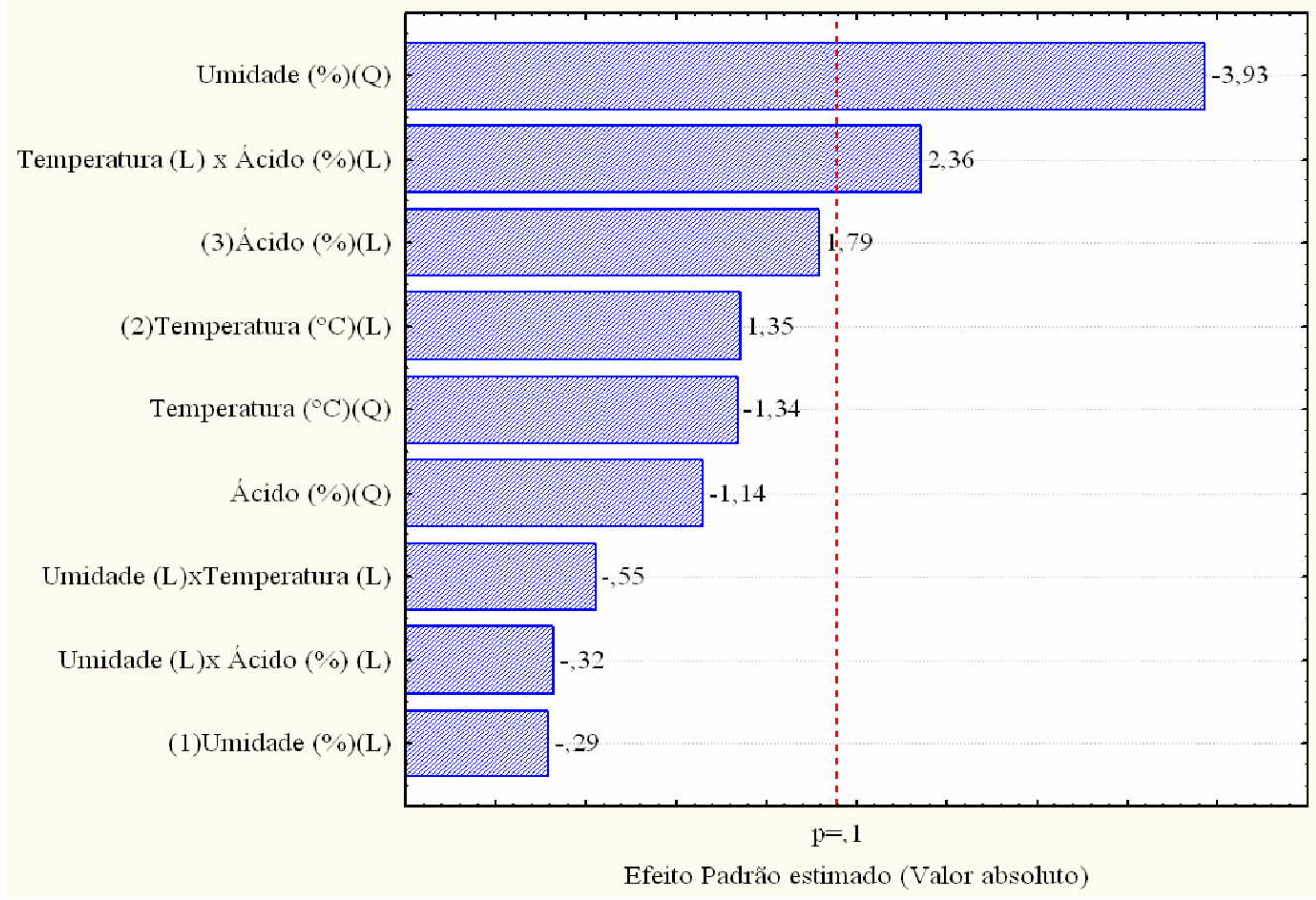

Figura 1 - Gráfico de Pareto mostrando os efeitos linear e quadrático e interação de variáveis independentes sobre o rendimento de açúcares fermentáveis a 90\% de confiança. 
De acordo com trabalhos que utilizaram o ácido fosfórico em reações de hidrólise, Zhang et al. (2007) observaram que a aplicação de ácido fosfórico a $50{ }^{\circ} \mathrm{C}$ dissolveu a hemicelulose e lignina, reduzindo a cristalinidade da celulose. Os mesmos autores enfatizaram que o ácido fosfórico concentrado $(>81 \%)$ foi um solvente adequado, porque a dissolução de celulose pelo ácido fosfórico ocorre a baixas temperaturas, o ácido fosfórico pode dissolver a celulose na presença de água, a celulose regenerada permanece numa forma amorfa adequada para a hidrólise, e o ácido fosforoso residual não tem efeitos inibidores sobre a hidrólise e de fermentação. Werle et al. (2013) observaram que o aumento da temperatura de $35^{\circ} \mathrm{C}$ para $60{ }^{\circ} \mathrm{C}$ melhorou o rendimento em açúcar fermentável na reação com folhas de palmeira. $\mathrm{O}$ mesmo aconteceu nesse trabalho, onde o melhor rendimento da reação foi com a temperatura de $58{ }^{\circ} \mathrm{C}$. Geddes et al. (2010), por sua vez, concluiu que a formação de compostos inibidores durante a reação foi mais baixa utilizando ácido fosfórico em comparação a ácido sulfúrico, em temperaturas elevadas.

A fim de otimizar a condição experimental para obter o máximo rendimento de açúcares fermentáveis, a Eq. 1 apresenta os termos significativos para o modelo empírico, de acordo com a hidrólise ácida:

$$
A F=112,78-39,55 \cdot U^{2}+28,13 \cdot T \cdot A
$$

onde $A F$ é o rendimento em açúcar fermentável, $U, T$ e $A$ representam a umidade, temperatura e concentração de ácido, respectivamente. O modelo foi validado pela análise de variância (ANOVA), sendo que o F calculado foi três vezes maior que o tabelado, ao nível de confiança de $90 \%$, e o coeficiente de correlação foi de 0,7915 . Os dados referentes ao modelo indicam bons ajustes aos dados experimentais, podendo ser utilizado como ferramenta para otimização do processo. A Fig. 2a demonstra a curva de contorno, correlacionando a umidade e a temperatura sobre o rendimento em açúcares fermentáveis, onde o máximo rendimento foi em torno de $100 \mathrm{~g} / \mathrm{kg}$ para o conteúdo de umidade de $60 \%$, e intervalo de temperatura de 45 a $62{ }^{\circ} \mathrm{C}$ aproximadamente. A Fig. $2 \mathrm{~b}$ apresenta a influência da concentração de ácido e porcentagem de umidade sobre o rendimento de açúcares fermentáveis. Da mesma forma que a figura anterior, o maior rendimento foi obtido com $60 \%$ de umidade, com concentração de ácido no intervalo de 18 a $28 \%$. 


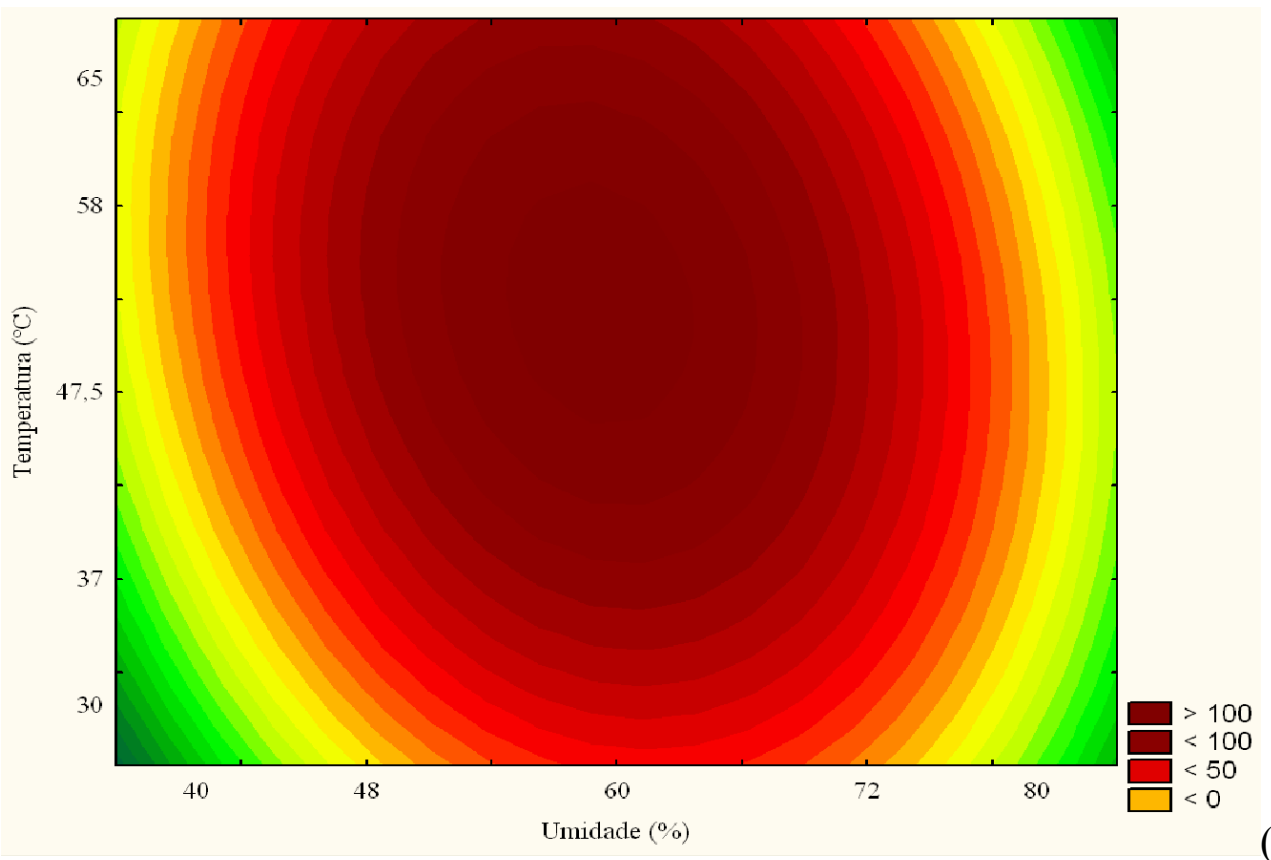

(a)

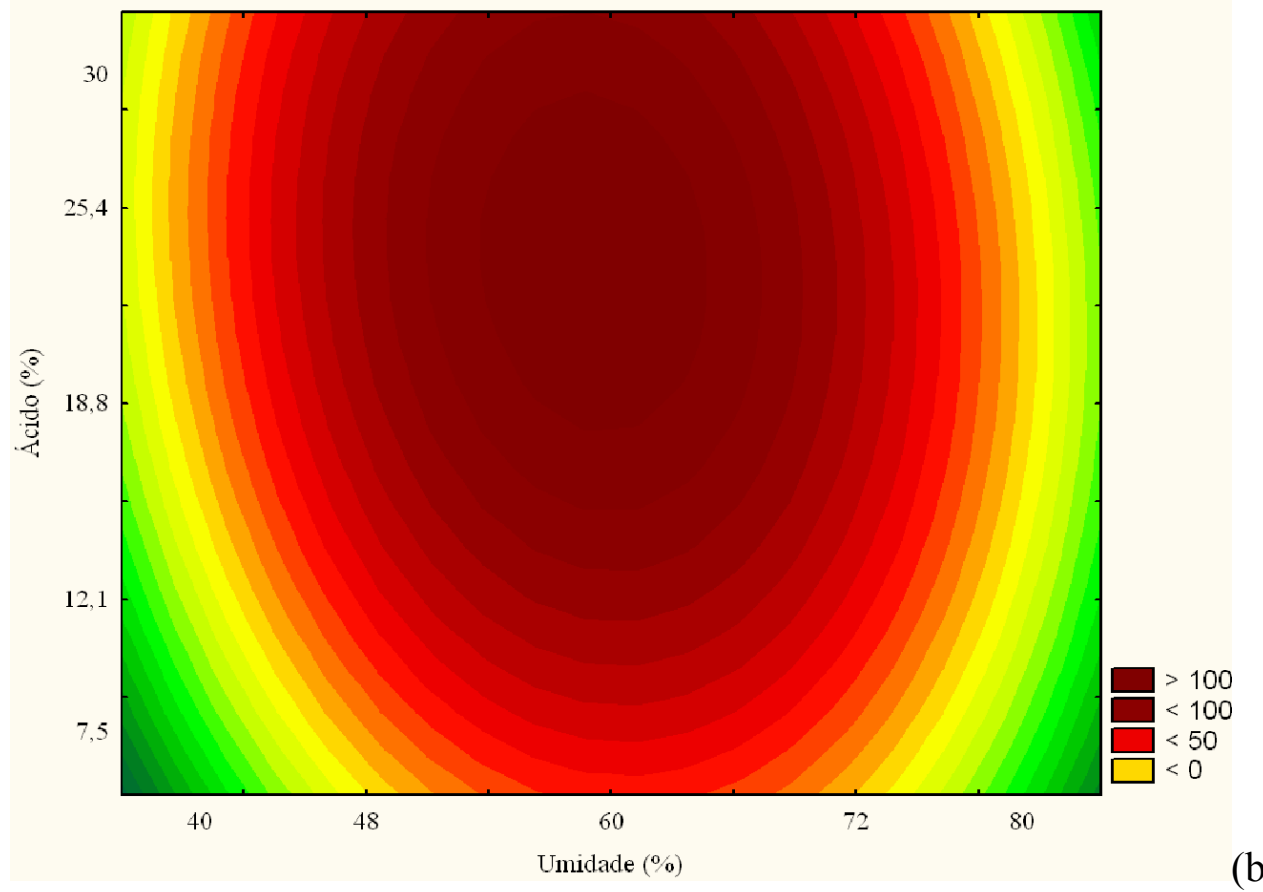

Figura 2- Curva de contorno mostrando a influência: (a) umidade e temperatura e (b) umidade e porcentagem de ácido sobre o rendimento de açúcares fermentáveis obtidos por hidrólise convencional ácida.

A Fig. 3 apresenta a influência da concentração de ácido e da temperatura sobre o rendimento da hidrólise ácida de casca de arroz. Nesse caso, o maior rendimento predito foi em torno de $150 \mathrm{~g} / \mathrm{kg}$, 
para a concentração de ácido no intervalo de 24 a $30 \%$, e temperatura de 58 a $65^{\circ} \mathrm{C}$.

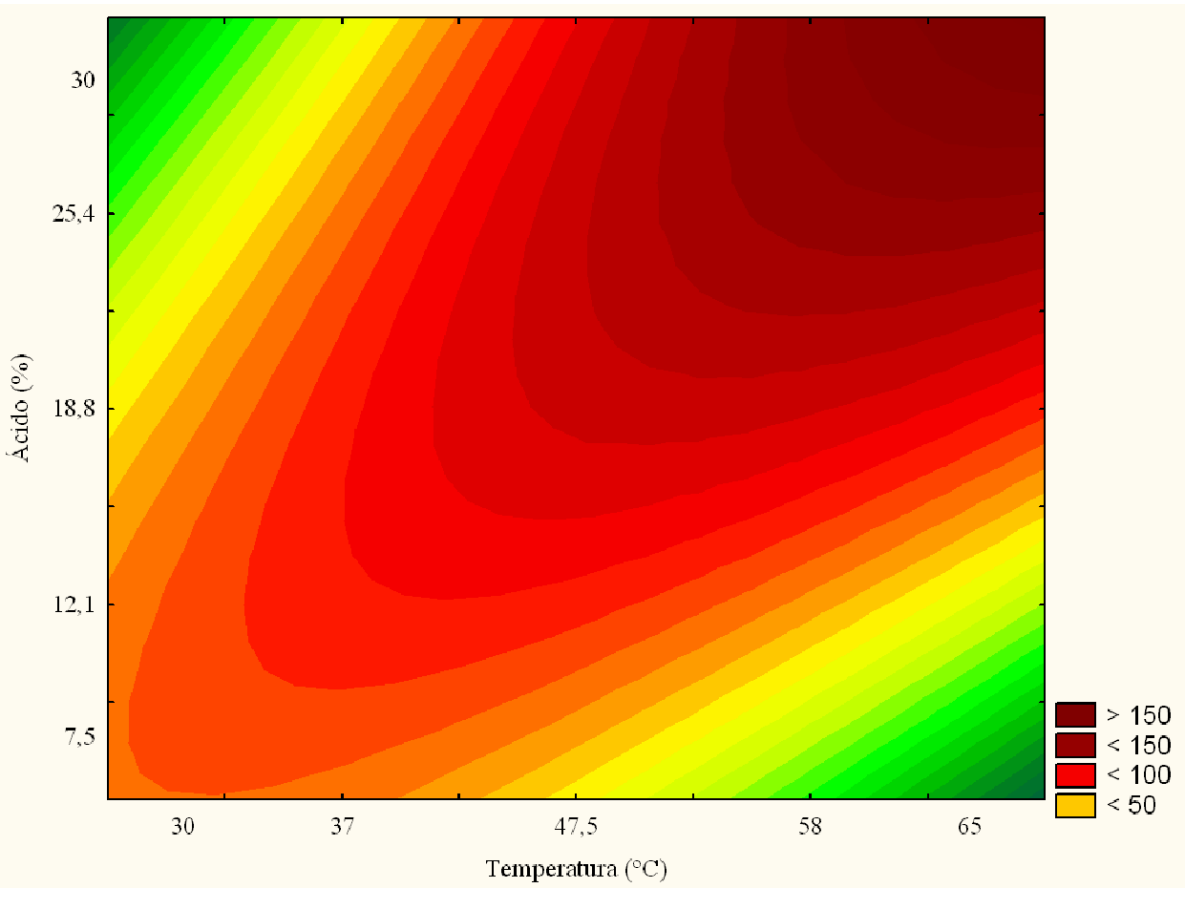

Figura 3 - Curva de contorno mostrando a influência da temperatura e porcentagem de ácido sobre o rendimento de açúcares fermentáveis obtidos por hidrólise convencional ácida. A umidade foi mantida no ponto central do DCCR (60\%).

\section{CONCLUSÕES}

Este artigo apresentou dados experimentais referentes à hidrólise ácida de casca de arroz, com o objetivo de obter açúcares fermentáveis, de forma convencional. A condição otimizada da análise de acordo com as curvas de contorno plotadas foi $60 \%$ de umidade, concentração de ácido fosfórico de $25,4 \%$ e temperatura de $65^{\circ} \mathrm{C}$, sendo obtido um rendimento de $141,1 \mathrm{~g} / \mathrm{kg}$. Isso demonstra que a utilização de um ácido fraco é relevante no processo de hidrólise. Para uma posterior fermentação e produção de etanol, o meio deveria receber uma suplementação com sacarose, fonte de nitrogênio, sais e a correção de pH para 6,5.

\section{REFERÊNCIAS}

DIAZ, A.; LE TOULLEC, J.; BLANDINO, A.; ORY, I.; CARO, I. Pretreatment of Rice Hulls with Alkaline Peroxide to Enhance Enzyme Hydrolysis for Ethanol Production. Chem. Eng. 
Trans., v. 32, p. 949-954, 2013.

VLAEV, L.T.; MARKOVSKA, I.G.; LYUBCHEV, L.A. Non-isothermal kinetics of pyrolysis of rice husk. Thermochim. Acta, v. 406, p.1-7, 2003.

WERLE, L. B.; GARCIA, J. C.; KUHN, R. C.; SCHWAAB, M.; FOLETTO, E. L.; CANCELIER, A.; JAHN, S. L.; MAZUTTI, M. A. Ultrasound-assisted acid hydrolysis of palm leaves (Roystonea oleracea) for production of fermentable sugars. Ind. Crop. Prod., v. 45, p. 28-132, 2013.

HICKERT, L. R. Otimização da hidrólise de casca de arroz (Oryza sativa) e avaliação da capacidade de bioconversão deste hidrolisado a etanol e xilitol por leveduras. Dissertação (Mestrado em Microbiologia Ambiental e Agrícola), Universidade Federal do Rio Grande do Sul, 2010.

HICKERT, L. R.; PEREIRA, F. C; SOUZA-CRUZ, P. B.; ROSA, C. A.; AYUB, M. A. Z. Ethanogenic fermentation of co-cultures of Candida shehatae HM 52.2 and Saccharomyces cerevisiae ICV D254 in synthetic medium and rice hull hydrolysate. Bioresour. Technol., v. 131, p. 508-514, 2013.

GAMEZ, S.; CABRIALES, J. J. G.; RAMIREZ, J. A.; GARROTE, G.; VÁZQUEZ, M. Study of the hydrolysis of sugar cane bagasse using phosphoric acid. J. Food Eng., v. 74, p. 78-88, 2006.

GEDDES, C.C.; PETERSON, J.J.; ROSLANDER, C.; ZACCHI, G.; MULLINNIX, M.T.; SHANMUGAM, K.T.; INGRAM, L.O. Optimizing the saccharification of sugar cane bagasse using dilute phosphoric acid followed by fungal cellulases. Bioresour. Technol. v. 101, p. 1851-1857, 2010.

ZHANG, Y. P.; DING, S.; MIELENZ, J. R.; CUI, J.; ELANDER, R.T.; LASER, M.; HIMMEL, M.E.; MCMILLAN, J.R.; LYND, L.R. Fractionating Recalcitrant Lignocellulose at Modest Reaction Conditions. Biotechnol Bioeng., v. 97, p. 214-223, 2007.

SAHA, B.; ITEN, L.; COTTA, M.; WU, V. Dilute Acid Pretreatment, Enzymatic Saccharification, and Fermentation of Rice Hulls to Ethanol. Biotechnol. Prog., v. 21, p. 816-822. 2005. 